\title{
Enterprise Human Resources Management Innovative Thinking in the Age of the Internet
}

\author{
Xingxiaoli \\ (QiongTai Normal University Hainan Haikou 571127)
}

Key words: The age of the Internet; Enterprise; Human resource management; Innovative thinking

\begin{abstract}
The advent of the age of the Internet has a direct influence on people's daily life and work. To promote the sustainable development of enterprises in current Internet social environment, constant innovative thinking in enterprise human resources management is required to lay the good foundation for current enterprise human resources management development. This article discusses enterprise human resources management innovative thinking under the age of the Internet.

With the development of market economy, enterprise competition is bigger and bigger. How to gain advantage in the fierce market competition becomes a problem enterprises have to face. Human resources, as one of core competitiveness of enterprises, are of great significance to the existence and development of enterprises. With the advent of information age and the era of "Internet +", innovate and reform enterprise human resources management by using the Internet, recruit and train more talents, and inject new vitality to the development of enterprises. These become important work to which enterprises must attach importance.
\end{abstract}

\section{The necessity of innovation in enterprise human resources management in the age of the Internet}

The most important thing in the age of the Internet is to think with the Internet. The Internet is primarily a technical innovation, and then leads to social and economic change. The Internet is the important communication tool to contact persons and society, people and enterprises. It connects reality and virtual world, and breaks through space and time limit in traditional communication. So in the Internet age, enterprise departments must actively face the changing market. Fully study and understand development direction and value of customers' requirements, products, enterprise, and timely respond to the changes, so the traditional enterprise management model must be innovated in the Internet age. Make a new understanding of the entire enterprise management system. The importance of talents is increasingly big in the 21st century, and human resources become the most important resource of enterprise, and have great influence on enterprise's survival and development. This influence has even decisive effect, thus effectively usage of the Internet thinking for human resources management can make faster enterprise human capital increment, create more economic benefit of enterprise, and realize enterprises' survival and healthy development.

\section{The present situation of enterprise human resources management in the age of the Internet}

Enterprise human resources management at present stage not only has traditional human resource management model and at the same time has the introduction of Internet thinking in our country. So the problems in enterprise human resources management at the present stage in our country are not only inherent problems of traditional human resource management, and the new problems appeared under the age of the Internet.

Traditional human resource management tends to release recruitment information through traditional media. New channels are relatively limited. So the transmission range is small and information transmission speed is slow. Recruitment costs are relatively high. This greatly influences the speed of recruitment, at the same time will result in an increase in recruitment costs. In addition, enterprise staff training model is relatively backward, and many companies now adopt lecture model in training. The training efficiency is low. Enterprise cadre staff performance appraisal has a certain degree of defects. Employee's job satisfaction and motivation are affected, which could lead to the loss of employees, and the benefit of the enterprise will be affected. Under the condition of the Internet, enterprise human resources management will be affected by the 
Internet thinking and impetuous society as a whole. At work, workers may lose enterprise identity leading to large staff mobility, which will affect the management and development of the enterprise.

\section{Specific measures of enterprise human resources management innovative thinking under the age of the Internet}

Enterprises should implement the specific work. Now the whole society is blundering. In the process, enterprise cadres need to continue to enhance discipline consciousness, restrain themselves in real time with rules and regulations, and adhere to principles and in strict accordance with the rules and regulations.

\section{A. Modern enterprise human resources management strategy should keep pace with The Times}

Information age is the product of modern society. Modern enterprises should adapt to The Times development in human resources management, insist on advancing with The Times, and abandon the traditional development strategy, and take innovative management strategies. Modern enterprise leadership and staff should have a correct understanding of human resource management information. Realize its important role, and plan the general idea of modern enterprise human resources management informationization from global perspective. The general idea can draw lessons from PDCA circulation pattern (Figure 1). PDCA cycle is also known as quality ring. It is the general model of management to continuously improve the quality of products. In it, $\mathrm{P}$ is Plan, $\mathrm{D}$ is Do, C is Check, and A is Action. Four processes of PDCA cycle are repeated and step-up, and is a progressive scientific management mode. As a systematic work, modern enterprise human resources management has high cost nature in innovation and implementation of information technology and need to think seriously about high loss failure. Do research and preparatory work, gradually improve and supplement through PDCA cycle, and guarantee that after modern enterprise human resources management strategy operation, there will be no directional deviation to avoid major mistakes in the implementation of strategic human resources management. After the end of a PDCA cycle, no matter human resource management is successful or not, modern enterprises all need to continue to study and prepare to enter the next cycle, prepare and plan should run through PDCA cycle and start again the front links. Through the scientific overall thought, undertake human resource management.

Figure 1 PDCA circulation patterns

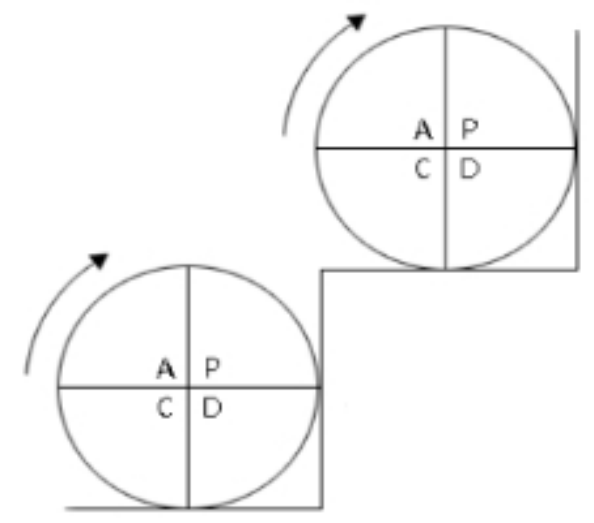

B. Application research of artificial intelligence and big data in the field of recruitment

Big data is usually generated automatically by machines. In the process of new data generation, manual work is not involved. It is automatically generated by the machine completely. By analyzing traditional data sources, it usually involves artificial factors. Second, big data is usually a kind of new data source, and not just the expansion collection of the existing data. Sometimes," more of the same type data" can also be reached at the other extreme, and becomes a new kind of data. Again, the design of many large data sources is not friendly. Traditional data sources usually are strictly defined in the start. Every bit of data has an important value; otherwise it will not contain the data bits. As the cost of storage space becomes little, big data sources at the beginning will not be strictly 
defined. It usually collects all information that may be used. Therefore, we may encounter data with a variety of desultorily and filled with garbage when analyze large data. Internet recruitment will greatly improve the efficiency of the enterprise personnel management and save personnel management.

\section{Human management through platform and big data}

In big data era, human resource management will rely on advanced technology platform, standardization, and timely information processing and management personnel. Improve the efficiency of human resource management and achieve efficient management. Implement effective management plan, perfect enterprise recruitment and training, and strengthen perfect assessment. Effectively improve staff's autonomous learning ability and professional skills. Improve enterprise innovation ability, and gain competitive advantage in the fierce competition in the market.

\section{Strict scientific assessment system}

Rigorous scientific assessment system is the inevitable trend of era and enterprise development. As information mobile phones and transmission platform, the Internet is used to establish evaluation model to be more rigorously scientific. At the same time, establish human shared information database to improve the use efficiency of human resources. Make a comprehensive understanding of employee information. Provide the basis for targeted measures and decisionmaking, and stimulate staff motivation and creativity.

E. Make early stage preparation for modern enterprise human resources management informationization

In the process of human resource management informatization, modern enterprises must do a good job of preparation. First of all, modern enterprise should be clear of the project team and responsibilities. Building project team is mainly to provide guarantee for leadership, mechanism and so on. Clear the responsibilities to ensure that the project team can achieve benign operation. The construction of a project team can be made by modern enterprise high-level personnel, relevant persons in charge of enterprise human resources management, enterprise information technology personnel, and professional executives, etc. Collect internal and external forces of modern enterprise human resource management and promote the formation of modern enterprise human resources management informationization. In the aspect of responsibilities distribution, modern enterprise project team can be divided into three levels, respectively, leadership decision, technology management, and business executives. All levels personnel are responsible for their own human resource management functions. Second, modern enterprise should do enterprise human resources management informationization planning well through preliminary work survey. In human resources management informatization planning, modern enterprise in our country should pay attention to information system and non-system plan and do a good job from transverse aspect. From the longitudinal aspect, strengthen tasks planning in human resources management informationization at various stages. Again, modern enterprises should also do early mobilization and training work well, aiming at human resources management informationization and improve the staff's acceptance and attention degree to human resources management informationization.

$F$. The innovation of modern enterprise human resource management information system design and implementation

Information system is the core of modern enterprise human resources management informationization. According to the characteristics of modern enterprise human resource management, the overall design of human resources management system must be more comprehensive on the content and the layout must be more reasonable, and it also needs to be more powerful. On the overall system integration design, not only do internal integration design, but also do external integration design; On the system structure design, modern enterprise may take B/S combined with $\mathrm{C} / \mathrm{S}$ mode to meet the diverse requirements of employees in modern enterprises system; On system deployment model design, the successful docking of techniques and modern enterprise human resource management model should be focused on. Unified management type modern enterprises can adopt centralized deployment mode. Strategic management type modern enterprises can adopt distributed deployment model and mixed management type modern 
enterprises can adopt mixed deployment mode. In the implementation process of information system, modern enterprises choose the appropriate construction mode based on their comprehensive consideration of various factors such as own resources and existing software foundation, enterprise culture and talent reserves. At present, our country's modern enterprises lack of professional talents and the investment is limited, but the development speed is quick. Information market is also increasingly mature, and enterprises can choose custom-made import mode. In the process of implementation, our country modern enterprises must also do a good job in human resource management information system maintenance and clarify maintenance cycle and maintenance personnel. After the installation of hardware and software, keep up with all the way, and backup regular cleaning is needed. In addition, modern enterprise should also build a long-term training mechanism to ensure that all information participants know the relevant knowledge and skills in the development of human resource management informatization to improve the depth and breadth of modern enterprise human resources management informationization in long-term application.

\section{Conclusion}

With the coming of information age, the Internet is fully developed. At present, people have entered the mobile Internet era. The Internet technology not only changes our life, but also changes our all walks of life. It affects our company and makes new directions and channels for enterprise management, enterprise human resources management, as an important content of enterprise management, is shouldering important tasks of enterprise talent recruitment, training and management, and it relates to the survival and development of the enterprise. Thus continuously innovation is needed to keep up with the trend of The Times. Inject new vitality to the development of the enterprises, and make enterprise management always walk at the front of the society development.

\section{Reference}

[1] Deng Jiehua. Enterprise human resources management innovation under the age of mobile Internet [J]. Journal of Modern Business, 2014, (14) : 95-96.

[2] Wang Jiaren. Modern enterprise human resources management innovation based on the "Internet +" and big data era [J]. Journal of Heilongjiang Science, 2016, 7 (5) : 152-153.

[3] Zhang Min, Ren Xiaoming. Enterprise human resource management informationization innovation construction [J]. Journ al of Management, 2011 (23) : 94.

[4] Miu Chunguang. Enterprise human resources management innovation fusion strategy in the era of Internet $+[\mathrm{J}]$. Market Modernization, 2016, (11) : 84-84.

[5] Chen Liudong, Tang Qi. Mobile Internet's enterprise human resources management innovation [J]. Journal of Oriental Culture, 2014, (22) : 159-159.

[6] Zhou Keshan. Introduction to electric power enterprise human resources informationization management [J]. Urban Construction Theory Research (Electronic Version), 2013, (22).

[7] Sun Shuhua. Modern enterprise human resources training work innovation [J]. China Power Education, 2007, (6) : 36 to 38.

[8] Cui Wa. Enterprise human resources management innovation analysis in "Internet +" [J]. Journal of National Business theoretical research, 2016, (10) : 46 -47. 